\title{
The in-vitro chemosensitivity of three cell lines derived from the VM/DK spontaneous murine astrocytoma
}

\author{
R BRADFORD,* J L DARLING, ${ }^{*} \dagger$ D G T THOMAS*
}

From the Gough-Cooper Department of Neurological Surgery, ${ }^{*}$ Institute of Neurology, and the Institute of Cancer Research, $\dagger$ London, $U K$

SUMmaRY Three cell lines, VM/Dk P497 P540 and P560 derived from the VM spontaneous murine astrocytoma have previously been fully characterised and found to differ in their degree of astrocytic differentiation. The in vitro chemosensitivity of the three lines has been investigated using the ${ }^{35} \mathrm{~S}$-methionine uptake assay. Differential chemosensitivity was found to exist between the cell lines. The pattern of chemosensitivity in relation to astrocytic differentiation was complex but the least differentiated cell line, P497, tended to be the least chemosensitive.

Wilson and Bates ${ }^{1}$ have proposed that the ideal brain tumour model for chemotherapy studies should be "a serially transplantable glioblastoma in the mouse". In addition Wilson ${ }^{2}$ has suggested that an ideal animal model for human glioma should be spontaneously arising, of glial origin, capable of intraparenchymal growth, uniformly fatal within a reasonable time period, capable of in vitro growth, transplantable both intracranially and subcutaneously in syngeneic animals and correlate with the therapeutic sensitivities of human gliomas. The choice of agents in current use for the chemotherapy of glioma has largely depended on results obtained from experimental models. Few, if any of these fulfil the criteria for an ideal therapeutic model of human glioma.

The inbred VM strain of mice has a high incidence of spontaneous astrocytomas. ${ }^{3}$ From one of these spontaneous murine astrocytomas (SMA) three permanent cell lines P497, P540 and P560 have been derived. ${ }^{4}$ These cell lines have been extensively characterised both in vitro and in vivo and have been shown to retain astrocytic features. ${ }^{5-8}$ They express the two astrocytic immuno-markers glial fibrillary acid protein (GFAP) and glutamine synthetase. ${ }^{7}$ In addition, transmission electron microscopy and immunocytochemistry have revealed that the lines show variation in their degree of astrocytic differ-

Address for reprint requests: Dr JL Darling, Gough-Cooper Department of Neurological Surgery, Institute of Neurology, Queen Square, London WCIN 3BG, UK.

Received 4 March 1986. Accepted 4 April 1986 entiation. Cell line P560 contains $10 \mathrm{~nm}$ filaments in $98 \%$ of cells and shows a strong positive cytoplasmic reaction for GFAP in vitro and is considered the best differentiated of the three lines. ${ }^{6}$ The least differentiated cell line $\mathbf{P} 497$ contains $10 \mathrm{~nm}$ filaments in only $15 \%$ of cells and is only weakly positive when stained for GFAP in vitro. Cell line P540 is of intermediate differentiation.

As an initial stage in the development of an in vitro-in vivo therapeutic model of glioma based on the VM cell lines we have investigated the in vitro chemosensitivity against a wide range of cytotoxic agents to determine if differential sensitivity exists among them and whether this is related to their degree of astrocytic differentiation.

\section{Materials and methods}

Cell Lines The cell lines VM/Dk P497, P540 and P560 were originally the gift of Dr DD Bigner, Duke University Medical Centre, USA. These cell lines were stored at the Institute of Neurology in the liquid nitrogen freezer. Chemosensitivity assays were performed on cell lines P497, P540 and P560 at in vitro passage levels $34-39,40-45$ and $24-29$, respectively. These passage levels were chosen since they fell within the range for which pathological characterisation had been performed. $^{7}$

Maintenance of cells in culture The methods used for the maintenance of cell cultures have previously been described. ${ }^{7}$ Drugs Drugs used in this study together with the range of concentrations are given in table 1. Drugs were dissolved in Ham's F10 medium (without foetal calf serum) apart from the nitrosoureas which were dissolved in absolute ethanol and C-PLAT which was dissolved in normal saline. Stock 
Table 1 Chemotherapeutic agents and range of concentrations used in chemosensitivity assays

\begin{tabular}{llc}
\hline Drug & Abbreviation & $\begin{array}{c}\text { Concentration range on } \\
\text { microtitration plate }(\mu \mathrm{g} / \mathrm{ml})\end{array}$ \\
\hline Procarbazine & PCB & $1000-4$ \\
Vincristine & VCR & $10-3 \cdot 12 \times 10^{-6}$ \\
CCNU* & CCNU & $40-0.013$ \\
BCNU† & BCNU & $40-0.013$ \\
Vindesine & VDS & $10-3 \cdot 12 \times 10^{-6}$ \\
Adriamycin & ADM & $10-10^{-4} \times 10^{-4}$ \\
Cis-platinum & C-PLAT & $10-10^{-4}$ \\
Bleomycin & BLM & $10-10^{-4}$ \\
5-Fluorouracil & 5-FU & $10-10^{-4}$ \\
\hline
\end{tabular}

*1-(2-chloroethyl)-3-cyclohexyl-1-nitrosourea

+1,3-bis(2-chloroethyl)-1-nitrosourea

solutions were stored at $-70^{\circ} \mathrm{C}$. Drug breakdown was not determined but assumed to be minimal at this temperature. Drug solutions were all diluted in Ham's F10 plus $10 \% \mathrm{v} / \mathrm{v}$ foetal calf serum with $50 \mathrm{IU} / \mathrm{ml}$ penicillin and $50 \mu \mathrm{g} / \mathrm{ml}$ streptomycin and buffered with $20 \mathrm{mM}$ Hepes.

Chemosensitivity Assay The chemosensitivity assay used was the ${ }^{35} \mathrm{~S}$-methionine assay which has been described in detail elsewhere. ${ }^{910}$ Briefly, monolayer cultures of P497, P540 and P560 were trypsinised in exponential growth phase and 96 well microtitration plates (Sterilin, UK) seeded with $2 \times 10^{3}$ cells per well. After 24 hours incubation at $37^{\circ} \mathrm{C}$, medium was removed by suction and $0.2 \mathrm{ml}$ of each drug dilution was added to quadruplicate wells of the plate. Two wells of each row were left free of drugs to act as controls. The drug containing medium was renewed 24 and 48 hours later to give a total drug exposure time of 72 hours. Drug solutions were then removed by suction and each well washed three times in HBSS and then filled with $0.2 \mathrm{ml}$ of fresh growth medium. Following a recovery period long enough to include one population doubling time $0.1 \mathrm{ml}$ of $2 \mu \mathrm{Ci} / \mathrm{ml}^{35} \mathrm{~S}$-methionine was added to each well and incubated for 4 hours. The plates were then washed in HBSS, fixed in methanol, extracted in ice-cold $10 \%$ trichloroacetic acid (BDH Chemicals, UK), washed in tap water and dried in methanol. Fifty microlitres of toluene based scintillation fluid (NE233, Nuclear Enterprises, UK) was added to each well and the plates dried by centrifugation. Autofluorograms were prepared by placing a sheet of X-ray film (Kodak, UK) under each plate and exposing them for 24-48 hours at $-70^{\circ} \mathrm{C}$. Quadruplicate determinations for each drug were performed on two separate occasions. The autofluorograms were analysed with a MR600 microplate reader (Dynatech, UK) which presents data as absorbance units. Using the absorbance reading for each well the incorporation of labelled amino acid was expressed as percentage of the mean of the control in that row and the dose of drug that inhibited protein synthesis by $50 \%$ (IDso) determined graphically. The mean value of the ID ID $_{50}$ for each drug was then calculated. Pairwise comparison of mean ID 50 's was performed using the Scheffé test. ${ }^{11}$

For all experiments cell counts were made daily of replicate plates of each cell line to determine the population doubling time and to ensure that cultures remained in exponential growth throughout the assay.
Results

The population doubling times for the three cell lines P497, P540 and P560 were 27.5, 30.5 and 34.8 hours respectively.

The results are shown in the fig and table 2 . It is clear that each cell line exhibits a different pattern of sensitivity to the nine drugs. Statistical analysis of the data was carried out using the Scheffé test which is a conservative method of performing multiple pairwise comparisons of means. P497 was significantly more resistant $(p<0.05)$ to PCB, 5-FU and VDS than P540, similarly, P497 was significantly more resistant to PCB, 5-FU and BLM than line P560. Cell line P560 was also more sensitive than P497 to C-PLAT and BCNU. Cell line P540 was significantly more sensitive than P560 to PCB, 5-FU and the vinca alkaloids, VCR and VDS but less sensitive to C-PLAT. Table 2

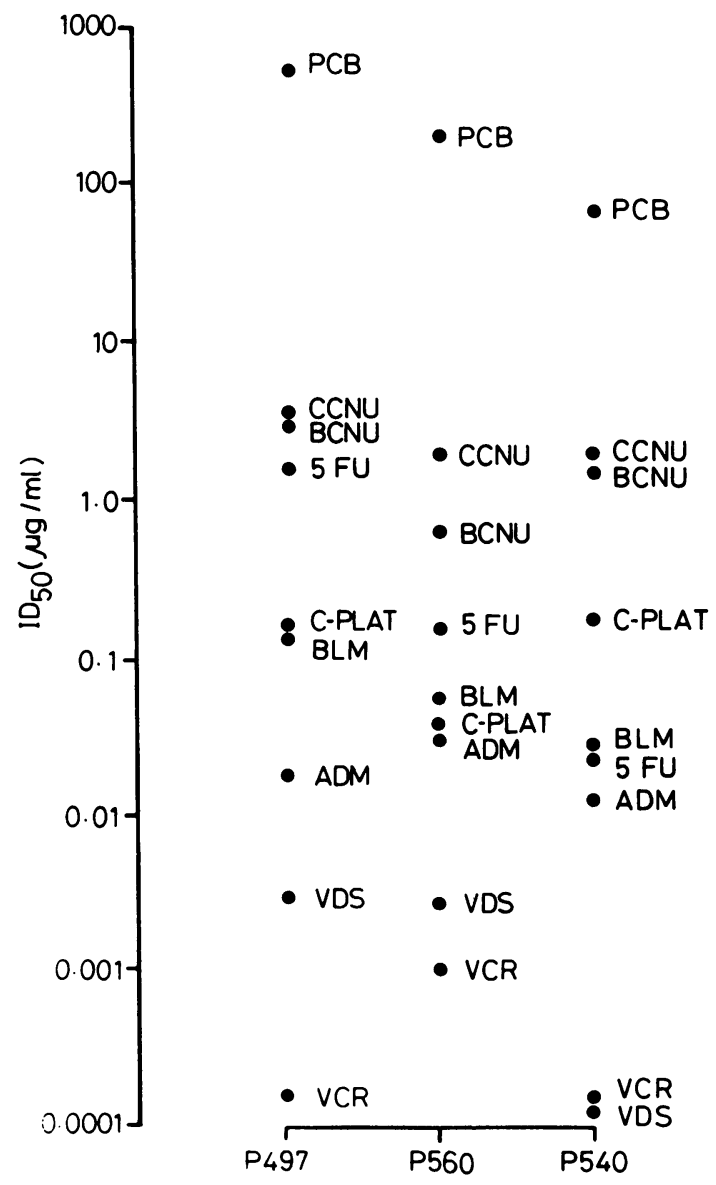

Fig The spectrum of in vitro chemosensitivity of the three $V M / D k$ cell lines. 
Table 2

\begin{tabular}{|c|c|c|c|c|}
\hline \multirow[b]{2}{*}{ Drug } & \multicolumn{4}{|c|}{ Mean $I D_{s 0} u g / m l \pm S E$} \\
\hline & $P 497$ & $P 540$ & $P 560$ & Fold difference* \\
\hline $\begin{array}{l}\text { PCB } \\
\text { VCR } \\
\text { CCNU } \\
\text { BCNU } \\
\text { VDS } \\
\text { ADM } \\
\text { C-PLAT } \\
\text { BLM } \\
\text { 5-FU }\end{array}$ & $\begin{aligned} & 543.0 \pm 23.9 \\
& 0.00018 \pm 0.00004 \\
& 3.68 \pm 0.27 \\
& 3.56 \pm 0.39 \\
& 0.0033 \pm 0.0009 \\
& 0.02 \pm 0.002 \\
& 0.17 \pm 0.03 \\
& 0.16 \pm 0.036 \\
& 1.68 \pm 0.26\end{aligned}$ & $\begin{aligned} & 79.0 \pm 5.0 \\
& 0.00018 \pm 0.00005 \\
& 2.25 \pm 0.18 \\
& 1.75 \pm 0.09 \\
& 0.00014 \pm 0.00001 \\
& 0.014 \pm 0.002 \\
& 0.20 \pm 0.02 \\
& 0.031 \pm 0.004 \\
& 0.03 \pm 0.002\end{aligned}$ & $\begin{aligned} 218.0 & \pm 7.5 \\
0.0012 & \pm 0.00013 \\
2.20 & \pm 0.35 \\
0.70 & \pm 0.06 \\
0.0032 & \pm 0.0003 \\
0.035 & \pm 0.0018 \\
0.043 & \pm 0.02 \\
0.062 & \pm 0.01 \\
0.19 & \pm 0.02\end{aligned}$ & $\begin{array}{r}6 \cdot 9 \\
6 \cdot 7 \\
1 \cdot 7 \\
5 \cdot 8 \\
23 \cdot 6 \\
2 \cdot 5 \\
4 \cdot 7 \\
5 \cdot 2 \\
56 \cdot 0\end{array}$ \\
\hline
\end{tabular}

${ }^{*}$ Least to most sensitive

also shows the number of fold difference in the ID 50 between the least and most sensitive cell line. The greatest range in sensitivity occurred between P497 and P540 for the cell cycle specific agents VDS and 5-FU where the ID 50 's varied between $23 \cdot 1$ and $56 \cdot 0$ fold respectively.

The cell lines were ranked in order of sensitivity (ID ${ }_{50}$ ) from least to most sensitive for each drug and shown in table 3 . No single cell line was consistently most or least sensitive to all of the nine drugs. However, the cell line considered to be the morphologically least differentiated, P497, tends to be less sensitive to more drugs than either of the other two lines. It has

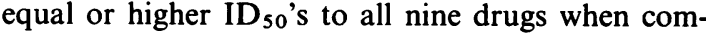
pared with the line of intermediate differentiation, P540. This trend is continued when P497 is compared with P560 which displays the greatest degree of astrocytic differentiation, although P560 is significantly more resistant to VCR than either of the other two lines. No clear pattern of ranking with regard to chemosensitivity emerges between cell lines P560 and P540.

\section{Discussion}

The ${ }^{35}$ S-methionine uptake assay has been used extensively in our laboratory for in vitro chemosensitivity studies on a large number of human glioma short term cultures. A range of sensitivity for 120 cultures has been established for PCB, VCR and CCNU. ${ }^{12}$ The mean ID $_{50}$ of the three VM/Dk cell lines for these three drugs falls within the range determined for human glioma cultures. There is therefore some correlation, at least in vitro, in therapeutic sensitivity between the VM/Dk cell lines and human glioma cultures.

Differential chemosensitivity of cell lines derived from a single neoplasm has been described previously in both human ${ }^{1314}$ and animal tumours. ${ }^{15}$ The data presented in this paper demonstrate that sensitivity to a given agent is also expressed differentially by the three VM/Dk cell lines. We can at present only spec- ulate on the reasons for the differences in chemosensitivity. Various mechanisms have been proposed to explain differential drug sensitivities between tumour cells. Differences in cell membrane properties may alter the transport of drugs into or out of cells. ${ }^{16}$ Intracellular drug metabolism may also differ such that there is variability in the conversion of anticancer drugs to active or inactive forms. ${ }^{13}$ The presence of alternative biochemical pathways may allow the cell to bypass the drug inhibited step. ${ }^{17}$ The ability of the cell to repair drug induced DNA damage is also an important factor for the survival of cells damaged by chemotherapy. ${ }^{18}$ For each agent any one of these mechanisms may be responsible for the pattern of chemosensitivity which has emerged for the three VM/Dk cell lines.

Patterns of cross-resistance and collateral sensitivity to chemotherapeutic agents have been investigated in a number of different tumour systems. Many inconsistencies have arisen between studies making interpretation of data difficult. It is of interest, however, that for the agents for which P497 is not the least sensitive, that is, ADM, VCR and C-PLAT, previously reported patterns of cross-resistance and collateral sensitivity exist. Cell line P560 has the highest $\mathrm{ID}_{50}$ to ADM and VCR. Cross-resistance between these two drugs has been reported frequently. ${ }^{1920}$ In

Table 3 Relative sensitivity of three $V M / D K S M A$ derived sublines

\begin{tabular}{|c|c|}
\hline Drug & Ranking* \\
\hline $\begin{array}{l}\text { PCB } \\
\text { VCR } \\
\text { CCNU } \\
\text { BCNU } \\
\text { VDS } \\
\text { ADM } \\
\text { C-PLAT } \\
\text { BLM } \\
\text { 5-Fu }\end{array}$ & $\begin{array}{l}\mathrm{P} 497>+\mathrm{P} 560>\mathrm{P} 540 \\
\mathrm{P} 560>\mathrm{P} 540=\mathrm{P} 497 \\
\mathrm{P} 497=\mathrm{P} 540=\mathrm{P} 560 \\
\mathrm{P} 497>\mathrm{P} 540=\mathrm{P} 560 \\
\mathrm{P} 497=\mathrm{P} 560>\mathrm{P} 540 \\
\mathrm{P} 560=\mathrm{P} 497=\mathrm{P} 540 \\
\mathrm{P} 540=\mathrm{P} 497>\mathrm{P} 560 \\
\mathrm{P} 497>\mathrm{P} 560=\mathrm{P} 540 \\
\mathrm{P} 497>\mathrm{P} 560>\mathrm{P} 540\end{array}$ \\
\hline
\end{tabular}

* Least to most sensitive

+Significant difference $(p<0.05)$ 
resistant tumour sublines, these agents can be shown to enter the cell but are then actively transported out. This results in a relatively low intracellular level of drug and thus to low cytotoxicity. ${ }^{2122} \mathrm{~A}$ common cellular efflux process could explain cross-resistance between the two drugs. P540 is the least sensitive to only one drug, C-PLAT, but is considerably more sensitive than the other two cell lines to the vinca alkaloid VDS. An impressive collateral sensitivity for VDS has been reported in vivo in a subline of the Erhlich ascites tumour selected for resistance to CPLAT. ${ }^{23}$ The mechanism of this collateral sensitivity remains to be explained and indeed it was not found in one of the few other studies of these two drugs. McMillan and coworkers ${ }^{24}$ reported cross-resistance between C-PLAT and VDS in a C-PLAT resistant murine mammary carcinoma. Clearly more data are required about these two drugs from different tumour systems before firm conclusions can be made, although some encouraging results have been obtained with a combination of VDS and C-PLAT in clinical chemotherapy. ${ }^{23}$

Little is known about differences in therapeutic sensitivities between human gliomas of different grades. Low grade gliomas are only rarely treated with chemotherapy and therefore clinical correlations are difficult. Indirect evidence from Burger and Vollmer ${ }^{25}$ suggests that high grade gliomas should be more responsive to adjuvant therapy. These authors estimated the cellularity of gliomas and correlated this with patient survival. They found a positive correlation between cellularity and survival in a group of patients treated with postoperative chemotherapy and radiotherapy. It was concluded that this was consistent with the idea that more primitive cells are more susceptible to these treatments. Animal models of glioma, which have been used extensively for therapeutic studies ${ }^{26}$ have provided little information on the relationship of tumour differentiation and chemosensitivity. The ependymoblastoma model of glioma comprises a group of four tumours said to be histologically similar. ${ }^{27}$ One of these tumours Ependymoblastoma $A$ is a mutant subline of the original ependymoblastoma and is considered to be more malignant than the parent line. ${ }^{27}$ These two tumours, however, show similar sensitivity in drug treated tumour-bearing mice. ${ }^{28}$ Human gliomas of various grades have been transplanted intracranially into nude mice. ${ }^{29}$ Generally, grade III and IV gliomas take and grow in a more predictable fashion than lower grade tumours ${ }^{29}$ and to date therapeutic experiments have not been reported on low grade human glioma xenografts. High grade gliomas growing in nude mice respond to clinically effective agents such as the nitrosoureas. However, different tumours of similar histological grade do not respond in the same way to any one particular agent. ${ }^{3031}$ Kornblith and coworkers $^{32}$ have also found that pathological grading of glioma is not strictly related to chemosensitivity. They studied the sensitivity of 42 gliomas of grade III and IV to BCNU using an in vitro microcytotoxicity assay. A wide variation in sensitivity existed between tumours of the same grade.

We have found that the pattern of chemosensitivity in relation to the degree of astrocytic differentiation is complex. Morphologically P497 is the least differentiated of the three cell lines. ${ }^{6}$ It is only weakly GFAP positive and contains $10 \mathrm{~nm}$ filaments in only a small percentage of cells. The presence of $10 \mathrm{~nm}$ filaments within cells is thought to be a reliable guide to the degree of astrocytic differentiation in experimental brain tumours. ${ }^{33} \mathrm{P} 497$ has a tendency to be the least chemosensitive of the three cell lines, although the differences in ID $_{50}$ for some of the agents is small. There is a theoretical basis for relative chemoresistance in less differentiated tumour cells. One mechanism of repair of DNA damage is associated with the degree of cellular differentiation. This involves the repair enzyme poly-ADP-ribose polymerase which is activated by DNA strand breaks. ${ }^{34}$ Higher poly-ADP-ribose polymerase activity is generally found in less differentiated, more rapidly growing cells. ${ }^{18}$ Less differentiated cells, such as P497, may have a higher capacity for the repair of DNA damage and therefore a greater ability to survive the effects of chemotherapeutic agents. Secondly gene amplification, which appears to be of considerable importance in developing drug resistance can easily be induced in undifferentiated cells whereas tumour cells showing some degree of differentiation undergo gene amplification only with difficulty. ${ }^{35}$

Although a number of animal brain tumour models have been developed for use in chemosensitivity studies $^{26}$ none has been based upon a tumour which has arisen spontaneously. Of the animal models in use the $9 \mathrm{~L}$ gliosarcoma in the rat is the only one to date which has been refined for both in vitro and in vivo chemotherapy studies. ${ }^{36} 37$ The tumour is biologically unstable, however, and whether its current sarcomatous nature detracts from clinical applications is unclear. The three cell lines derived from the VM/Dk spontaneous astrocytoma offer the potential for the development of an animal brain tumour model which fulfills many of the criteria of Wilson. ${ }^{2}$ In addition it allows the relationship between chemosensitivity and astrocytic differentiation to be explored both in vitro and in vivo. The present study forms the basis for further development of this model in which in vivo chemosensitivity of the three cell lines will be determined. Whether the in vitro pattern of differential sensitivity observed in this study will be reflected in the animal model remains to be seen. 


\section{References}

1 Wilson CB, Bates EA. Transplantable brain tumors. In: Kirsch WM, Paoletti EG, eds. The Experimental Biology of Brain Tumors Springfield: Charles C Thomas, 1972:19-56.

2 Wilson CB. Brain tumor models for experimental therapy. In: Laerum OD, Bigner DD, Rajewsky MF, eds. Biology of Brain Tumors. Geneva: UICC Technical Report Series 26, 1978:185-99.

3 Fraser $H$. Spontaneous astrocytoma in mice and its transmission with viable cells. In: Clifford Rose F, Behan PO, eds. Animal Models of Neurological Disease. London: Pitman, 1980:393-404.

4 Serano RD, Pegram CN, Bigner DD. Tumorigenic cell culture lines from a spontaneous VM/DK murine astrocytoma (SMA). Acta Neuropathol 1980;51:53-64.

5 Pilkington GJ, Darling JL, Thomas DGT, Lantos PL. In vivo and in vitro studies of a transplantable murine astrocytoma using transmission and scanning electron microscopy. Neuropathol Appl Neurobiol 1982;8:244.

6 Pilkington GJ, Lantos PL, Darling JL, Thomas DGT. Three cell lines from a spontaneous murine astrocytoma show variation in astrocytic differentiation. Neurosci Lett 1982;34:315-20.

7 Pilkington GJ, Darling JL, Lantos PL, Thomas DGT. Cell lines (VMDk) derived from a spontaneous murine astrocytoma. Morphological and Immunocytochemical characterization. J Neurol Sci 1983;62: 115-39.

8 Pilkington GJ, Darling JL, Lantos PL, Thomas DGT. Tumorigenicity of cell lines (VMDk) derived from a spontaneous murine astrocytoma. Histology, fine structure and immunocytochemistry of tumours. J Neurol Sci 1985;71:145-64.

9 Thomas DGT, Darling JL, Freshney RI, Morgan D. In vitro chemosensitivity assay of human glioma by scintillation autofluorography. In: Paoletti P, Walker MD, Butti H, Kneich R, eds. Multidisciplinary Aspects of Brain Tumour Therapy. Amsterdam: Elsevier, 1979: 19-35.

10 Morgan D, Freshney RI, Darling JL, Thomas DGT, Celik F. Assays of anticancer drugs in tissue culture: Cell cultures of biopsies from human astrocytoma. Br J Cancer 1983;47:205-14.

11 Scheffé H. The Analysis of Variance. New York: Wiley, 1959.

12 Darling JL. Chemosensitivity testing in the treatment of malignant gliomas. In: Homburger F, ed. Progress in Experimental Tumour Research Vol 29 Basel: Karger, 1985:123-30.

13 Barranco SC, Drewinko B, Ho D, Humphrey RM, Romsdahl MM. Differential sensitivities of human melanoma cells grown in vitro to arabinosylcytosine. Cancer Res 1972;32:2733-6.

14 Barranco SC, Drewinko B, Humphrey RM. Differential response of human melanoma cells to 1,3-bis-(2-chloroethyl)-1-nitrosourea and bleomycin. Mutation Res 1973;19:277-80.

15 Heppner GH, Dexter DL, De Nucci T, Miller FR, Calabresi P. Heterogeneity in drug sensitivity among tumour cell subpopulations of a single mammary tumour. Cancer Res 1978;38:3758-63.

16 Biedler JL, Riehm H, Peterson RHF, Spengler BA. Membrane-mediated drug resistance and phenotypic reversion to normal growth behaviour of Chinese hamster cells. J Natl Cancer Inst 1975;55:671-80.

17 Barranco SC, Humphrey RM. The effects of B-2deoxythioguanosine on survival and progression in mammalian cells. Cancer Res 1971;31:583-6.

18 Harris AL. DNA repair: relationship to drug and radiation resistance, metastasis and growth factors. Int J Radiat Biol 1985;48:675-90.

19 Dano K. Experimentally-developed cellular resistance to daunomycin. Acta Pathol Microbiol Scand (A) 1976;256 (suppl):35-78.

20 Inaba M, Fujikura R, Sakurai Y. Active efflux common to vincristine and daunorubicin in vincristine-resistant P388 leukemia. Biochem Pharmacol 1981;30:1863-5.

21 Dano K. Active outward transport of daunomycin in resistant Ehrlich ascites tumor cells. Biochem Biophys Acta 1973;323:466-83.

22 Skovsgaard T. Mechanisms of cross-resistance between vincristine and daunorubicin in Ehrlich ascites tumor cells. Cancer Res 1978;38:4722-7.

23 Seeber S, Osieka R, Schmidt CG, Achterrath W, Crooke ST. In vivo resistance towards anthracylines, etoposide and cis-diamminedichloroplatinum (II). Cancer Res 1982;42:4719-25.

24 McMillan TJ, Stephens TC, Steel GG. Development of drug resistance in a murine mammary tumour. $\mathrm{Br} J$ Cancer 1985;52:823-32.

25 Burger PC, Vollmer RT. Histologic factors of prognostic significance in the glioblastoma multiforme. Cancer 1980;46:1179-86.

26 Schold SC, Bigner DD. A review of animal brain tumour models that have been used for therapeutic studies. In: Walker MD, ed. Oncology of the Nervous System. Boston: Martinus Nijhoff, 1983:31-63.

27 Ausman JI, Shapiro WR, Rall DP. Studies on the chemotherapy of experimental brain tumours: Development of an experimental model. Cancer Res 1970;30: $2394-400$.

28 Shapiro WR, Ausman JI, Rall DP. Studies on the chemotherapy of experimental brain tumours: Evaluation of 1,3-bis(2-chloroethyl)-1-nitrosourea, cyclophosphamide, mithramycin, and methotrexate. Cancer Res 1970;30:2401-13.

29 Basler GA, Shapiro WR. Brain tumour research with nude mice. In: Fogh J, Giovanella BG, eds. The Nude Mouse in Experimental and Clinical Research. Vol 2. New York: Academic Press, 1982:475-90.

30 Shapiro WR, Basler GA, Chernik NL, Posner JB. Human brain tumor transplantation into nude mice. $J$ Natn Cancer Inst 1979;62:447-53.

31 Shapiro WR, Basler GA. Chemotherapy of human brain tumors transplanted into nude mice. In: Paoletti $P$, Walker MD, Butti H, Kneich R, eds. Multidisciplinary Aspects of Brain Tumor Therapy. Amsterdam: Elsevier, 1979:309-16.

32 Kornblith P, Smith B, Leonard L. Response of cultured human brain tumors to nitrosoureas: Correlation with clinical data. Cancer 1981;47:255-65.

33 Lantos PL. The distribution and role of microtubules and 
filaments in the neoplastic astrocytes of experimental gliomas. Neuropathol Appl Neurobiol 1977;3:281-96.

34 Kameshita I, Matsuda Z, Taniguchi T, Shizuta T. Poly(ADP-ribose) synthetase. J Biol Chem 1984;259: 4770-6.

35 Fox $M$. Gene amplification and drug resistance. Nature 1984;307:212-3.

36 Rosenblum ML, Knebel KD, Wheeler KT, Barker M,

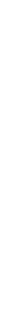

Wilson CB. Development of an in vitro colony formation assay for the evaluation of in vivo chemotherapy of a rat brain tumour. In Vitro 1975; 11:264-73.

37 Weizaecker M, Deen DF, Rosenblum ML, Hoshino T, Gutin PH, Barker M. The 9L rat brain tumour: description and application of an animal model. $J$ Neurol 1981;224:183-92. 